AperTO - Archivio Istituzionale Open Access dell'Università di Torino

\title{
Reappraisal of an old cheap method for marking the European hedgehog
}

\section{This is the author's manuscript}

Original Citation:

\section{Availability:}

This version is available http://hdl.handle.net/2318/1615298

since 2017-01-17T14:46:09Z

Published version:

DOI:10.1007/s13364-014-0210-0

Terms of use:

Open Access

Anyone can freely access the full text of works made available as "Open Access". Works made available under a Creative Commons license can be used according to the terms and conditions of said license. Use of all other works requires consent of the right holder (author or publisher) if not exempted from copyright protection by the applicable law. 
This is the author's final version of the contribution published as:

Mori, Emiliano; Menchetti, Mattia; Bertolino, Sandro; Mazza, Giuseppe; Ancillotto, Leonardo. Reappraisal of an old cheap method for marking the European hedgehog. MAMMAL RESEARCH. 60 (2) pp: 189-193. DOI: $10.1007 / \mathrm{s} 13364-014-0210-0$

The publisher's version is available at:

http://link.springer.com/content/pdf/10.1007/s13364-014-0210-0

When citing, please refer to the published version.

Link to this full text:

http://hdl.handle.net/2318/1615298 


\title{
Reappraisal of an old cheap method for marking the European hedgehog
}

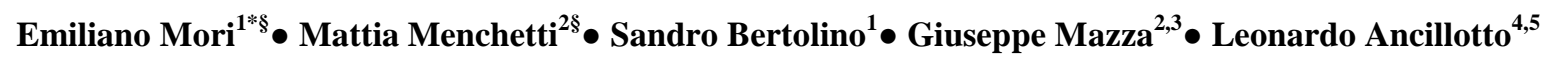

1. Department of Agricultural, Forest and Food Sciences, University of Turin, Grugliasco (Turin), Italy;

2. Department of Biology, University of Florence, Florence, Italy;

3. CRA-ABP, Consiglio per la Ricerca e la sperimentazione in Agricoltura, Florence, Italy;

4. Department of Biology and Biotechnologies "Charles Darwin", University of Rome "La Sapienza", Rome, Italy;

5. Wildlife Research Unit, Laboratorio di Ecologia Applicata, Dipartimento di Agraria, Università degli Studi di Napoli Federico II.

$\S$ These authors contributed equally to the manuscript

*Corresponding Author: Emiliano Mori, DISAFA, University of Turin, Largo P. Braccini 2-10095 Grugliasco (TO), Italy. Phone number: 0039333 1820342; Email: moriemiliano@ tiscali.it.

\begin{abstract}
Marking quilled animals for individual recognition may be challenging. This is particularly true for European hedgehogs Erinaceus europaeus, whose defense mechanism involves the concealment of muzzle and underparts. Heat-shrink tubes have been widely used to mark quills but they do not adapt to the morphological structure of the spines and are rapidly lost, thus reducing method effectiveness. We adapted a cheap and ethical method used to mark crested porcupine quills, which involves the use of coloured adhesive tapes applied to quills. The retention period of this marking technique lasts up to nine months, allowing short-term field studies and possibly dispersal distances measurements. The method could be improved by doubling the number of marked spines and by reapplying adhesive tape at every recapture event. Moreover, the use of a marking code can be obtained by subdividing the body of the hedgehog into six body areas, to increase the number of marking possibilities, through the combination of tape colours and body areas.
\end{abstract}

Keywords: Erinaceus europaeus, quill marking, adhesive tape, retention period, dispersal.

\section{Introduction}

Ecological studies involving population dynamics, dispersal movements, spatial behaviour and density estimates require individuals to be marked for future recognition and identification (Silvy et al. 2005). Individual recognition without direct manipulation is possible only for a few species of vertebrates, presenting particular fur or spot patterns (e.g. newts: Cicek and Ayaz 2011; yellow-bellied toads: Mori and Giovani 2012; spotted felids: Anile et al. 2012; dolphins: Sayigh et al. 1998). With regard to small mammals, this is possible only for few species with markedly variable pelage color among individuals (e.g. Callosciurus finlaysonii: Mazzoglio et al. 2007). For other species manipulation by man and application of devices are necessary to distinguish among different individuals.

The marking methods used for small mammals included cheap techniques, such as toe or ear clipping and hair cutting. The first two methods may affect spatial and antipredatory behaviour of the studied species (Lindner and Fuelling 2002; Borges-Landaez and Shine 2003); furthermore, an ethic limit on the number of toes or ear incisions to be cut greatly reduces the number of different possible markings (Petit et al. 2012). On the other hand, hair clipping represents only a short-term method, as markings disappear after the individual molts. Moreover, this technique is also difficult to read if the pelage of the animal is wet when recaptured. Ear tagging is substantially inapplicable in species with small or thin ears, as well as in species which practice allogrooming 
(Pigozzi 1988); tattoo and hair painting may represent useful techniques for some species, but are not always applicable due to limited space on the mammal's body (Petit et al. 2012).

We tested the effectiveness of a cheap and easy to apply method for marking quilled/spiny mammals. We chose the European hedgehog Erinaceus europaeus as a model species, since this is one of the most widespread and synanthropic mammals in Europe (Mitchell-Jones et al. 1999) and because it is characterized by a stocky body covered with dense and short spines $(\mathrm{N}=8400 \pm 300$ per individual, average length $=20-30 \mathrm{~mm}$, Pucek 1981; Morris 2006) on the dorsal region. Its ventral parts are not easy to manipulate because of its defense mechanism to roll into a ball with the spines facing outward (Reeve 1994). Due to its locomotion physiology and the habitats used (Boitani and Reggiani 1984; Doncaster et al. 2001; Riber 2006), the application of other marking methods such as spine painting (Campbell 1973; Lindner and Fuelling 2002) seems to be poorly efficient, since paint markings easily fade due to frequent friction with substrate. All of these considerations lead to the conclusion that marking E. europaeus for individual recognition is challenging, mainly because of its physical structure, which may also decrease the possibility to apply ear tags without sedation. In Appendix I we report a list of published work regarding the marking methods used for hedgehog.

While radio-tracking of each individual may last up to 8-12 months (Boitani and Reggiani 1984; Haigh et al. 2013), data on marking retention of other methods are not reported within the cited works (see table in Appendix I), with the exception of the spool-and-thread method, which did not last more than one night (Shanahan et al. 2007). Colored heat shrink tubings commonly used to insulate wires have been used to mark hedgehog, by placing them over some spines. Different colours or different marking areas on the body of the hedgehog may allow researchers to identify individuals also at a distance through a spot light (Campbell 1973; Norbury 2006; Dowding et al. 2010). This method do not alter the behaviour of the marked individuals, nor their exposure to predators because of their nocturnal habits (Pigozzi 1988). Color-coding using combinations of colors and placement on the hedgehog is useful while enough tubes remain on the hedgehog.

We propose an economic quill marking method, already used for crested porcupines (Pigozzi 1988) to maximize adhesion of markings to quills, which is ethically acceptable, harmless to hedgehogs, time saving and clearly visible at a distance.

\section{Materials and Methods}

The study area (about 750 ha) is located in a rural hilly landscape (475-650 m a.s.1.) in Southern Tuscany (Central Italy). Habitats in the study site (province of Grosseto, Central Italy: 474-1045 m a.s.1.) included mixed deciduous woodlands $(69 \%)$, fallow fields $(13 \%)$, cultivated fields $(5 \%)$, pinewoods $(3 \%)$, human settlements (2\%) and scrubwood (8\%, see also Mori et al. 2014).

Hedgehogs were captured through traps used in the framework of a research project on the ecology of the crested porcupines and by chance encounters. Recaptures occurred during radiotracking of crested porcupines and monitoring of nocturnal raptors and while traveling two $3 \mathrm{~km}$ line transects, three nights a week, between July and October 2011, and between March and May 2012. The first transect was located in a deciduous woodland (Forcoli oakwood, $43.087817^{\circ} \mathrm{N}-11.020083^{\circ} \mathrm{E}$ - hereafter DW), the second one within a human settlement (village of Prata, $43.083111^{\circ} \mathrm{N}, 10.985565^{\circ} \mathrm{E}$, hereafter HS). Body weight and sex of captured individuals were recorded. Animals weighting more than $600 \mathrm{~g}$ were considered as adults (Parkes 1975; Haigh et al. 2014).

Marking involved the application of $2 \mathrm{~cm}$ long strips of plastic adhesive tape, usually used to repair electrical cables on 20 quills (Pigozzi 1988). We used tapes of 10 different colours to allow individual recognition in each study site. Each individual was marked with 20 strips of the same colour, located randomly in the dorsal region of the individual. Handling required a maximum of 15 minutes for each hedgehog, which was then released at the point of capture. Recaptures occurred by visual sampling and handling lasted only for the time employed to recount marked quills (1-2 minutes).

The first two captured animals were marked with a single turn of tape around the quill, with the extremities of the strip joined to create a kind of colored flag (Method 1: Figure 1A). This allowed rapid recognition at a distance, but the marking lasted for a very short time (over 50\% tapes lost in 3 days). So, the coloured tape was turned twice around each quill, closing the ends of the strip on the quill itself (Method 2: Figure 1B).

Differences in number of recaptures and maximum distance from marking point between sexes and age classes were evaluated using Mann-Whitney $U$-test, since measurements were not normally distributed (Shapiro-Wilk normality tests: $\mathrm{W}=0.741-0.0002, \mathrm{P}$-value $=0.003-0.010)$. Means are reported $\pm \mathrm{SD}$.

\section{Results and Discussion}

A total of 12 hedgehogs ( 8 males, 4 females) was captured and marked with Method $2(\mathrm{DW}, \mathrm{N}=8 ; \mathrm{HS}, \mathrm{N}=4)$; four of them were marked and recaptured after hibernation (November-March: Table 1). Two individuals, were never recaptured (Table 1). Although more than half markings were lost in nine months (Figure 2), a road-killed 
individual was found after nine months with nine marked quills still present. No other marked individual has been recaptured after this one.

Juveniles were observed at higher distances than adults from the sites of their respective first capture (MannWhitney $U$-test $=0 ; P=0.009$ ), while distances were not significantly different between sexes (Mann-Whitney $U$-test $=8, P=0.4762$ ). All adult individuals and two juveniles were recaptured within an average radius of 650 $\pm 220 \mathrm{~m}$ from the site of first capture. The other juveniles were recaptured within an range of $463 \pm 338 \mathrm{~m} ; 80 \%$ of recaptures of young individuals occurred within 3-4 months after the application of adhesive tapes. Only two juveniles, one from DW and one from HS were road-killed, as adults, after seven and nine months from marking and at a distance of 3,766 and 2,953 m from their capture sites, respectively.

The marking method proposed in this study seems to be effective to analyze phylopatry and dispersal movements of hedgehogs. Colored tapes are also more easily applicable than ear tags in a species whose defense mechanism involves the ability to roll into a ball, and are longer lasting than spool-and-thread (Shanahan et al. 2007).

Quills of crested porcupines are longer than those of hedgehogs (Mohr 1965) and easily released by contact or drop out when the animal shakes its body, as loosely rooted (Mori et al. 2014). By contrast, quills of hedgehogs are well rooted and more rarely lost while individuals are walking or contacting with environment/other hedgehogs (Reeve 1994): thus, marking may be retained for a longer time. The reduction in observations of marked hedgehogs showed in Fig 2 may be due to the movement of hedgehogs off the study site rather than to the loss of marked quills. Moreover, after the ninth month, last marked hedgehogs may have been moved from the study site, or died while still retaining the marked spines. The method could be implemented by reapplying the missing tape strips at each recapture event or by marking a greater number of spines at the first capture.

The use of a marking code can be obtained by subdividing the body of the hedgehog into up to six body areas (Figure 3). This method may greatly increase the number of different marking possibilities, through the combination of tape colours and body areas. Considering that at least ten adhesive tape colours are commercially available, it should be possible to mark between 60 (using one body area) and 151,200 (using six body areas) different individuals.

Adults seem to be more phylopatric than juveniles and they are always recaptured in the surroundings of the areas of first capture (Reeve 1994). European hedgehogs become self-sufficient at the age of two months, then they move away from the mother and reach sexual maturity at about one year of life (Reeve 1994). This would explain the high rate of recapture of young hedgehogs during the first 3-4 months after the first capture, and their subsequent disappearance from the study site. Maximum dispersal distances traveled by hedgehogs in unfavorable habitats (farmlands in UK) may reach $10 \mathrm{~km}$, although, in general, they reach around $4 \mathrm{~km}$ (Doncaster et al 2001). The linear distances at which two road-killed hedgehogs found in our study (3766 and $2953 \mathrm{~m}$ ) are compatible with dispersal distances known from literature (Morris 1988; Jones and Norbury 2006; Molony et al. 2006; Dowding et al. 2010). Interestingly, the two individuals were recaptured a number of times around first capture areas before the supposed dispersal events.

Although the limited number of recaptures does not allow us to infer general conclusions about the spatial behaviour of the European hedgehog in the study area, our results in terms of spatial movements (dispersal patterns) seem to be consistent with Boitani and Reggiani (1984).

In conclusion, we highlight that the method we propose is cheap, time saving and efficient in evaluating the spatial behaviour of small bodied spiny mammals, i.e. very difficult mammals to be marked, and thus can be used as main method, e.g. in case of low-funding (Cagnacci et al. 2012), or as supplementary to other techniques (e.g. radiotracking).

\section{Acknowledgements}

Authors would like to thank E. Cortonesi and M. Ricci for their field work. G, Petri kindly revised the English language of our manuscript. Two anonymous reviewers improved the first draft of this paper.

\section{References}

Anile S, Arrabito C, Mazzamuto MV, Scornavacca D, Ragni B (2012) A non-invasive monitoring of European wildcat (Felis silvestris silvestris) in Sicily using hair trapping and camera trapping: does scented lure work? Hystrix, It J. Mammal 23: 44-49.

Boitani L, Reggiani G (1984) Movements and activity patterns of hedgehogs (Erinaceus europaeus) in Mediterranean coastal habitats. Zeitschrift für Säugetierkunde 49: 193-206.

Borges-Landaez PA, Shine R (2003) Influence of toe-clipping on running speed in Eulamprus quoyii, an Australian scincid lizard. J Herpetol 37: 592-595. 
Cagnacci F, Cardini A, Ciucci P, Ferrari N, Mortelliti A, Preatoni DG,, Russo D, Scandura M, Wauters LA, Amori G (2012) Less is more: a researcher's survival guide in times of economic crisis. Hystrix, It J. Mammal 23: 1-7.

Campbell PA (1973) The feeding behaviour of the hedgehog (Erinaceus europaeus L.) in pasture land in New Zealand. Proc New Zeal Ecol Soc 20: 35-40.

Cicek K, Ayaz D (2011) New data on facultative paedomorphism of the smooth newt, Lissotriton vulgaris, in Western Anatolia, Turkey. J Freshw Ecol 26: 99-103.

Doncaster CP, Rondinini C, Johnson PCD (2001) Field test for environmental correlates of dispersal in hedgehogs Erinaceus europaeus. J Anim Ecol 70: 33-46.

Dowding CV, Harris S, Poulton S, Baker PJ (2006) Nocturnal ranging behaviour of urban hedgehogs, Erinaceus europaeus, in relation to risk and reward. Anim Behav 80: 13-21.

Driezen K, Andriasen F, Rondinini C, Doncaster CP, Matthysen E (2007) Evaluating least-cost model predictions with empirical dispersal data: a case-study using radiotracking data of hedgehogs (Erinaceus europaeus). Ecol Model 209: 314-322.

Haigh A, O'Riordan RM, Butler F (2013) Habitat selection, philopatry, and spatial segregation in rural Irish hedgehogs. Mammalia 77: 163-172.

Haigh A, Kelly M, Butler F, O’Riordan RM (2014) Non-invasive methods of separating hedgehogs (Erinaceus europaeus) age classes and an investigation into the age structure of road kills. Acta Theriol 59: 165-171.

Jones C, Norbury G (2006) Habitat use as a predictor of nest raiding by individual hedgehogs Erinaceus europaeus in New Zealand. Pacific Cons Biol 12: 180-188.

Jones C, Norbury G, Bell T (2013) Impacts of introduced European hedgehogs on endemic skinks and weta in tussock grassland. Wildl Res 40: 36-44.

Lindner E, Fuelling O (2002) Marking methods in small mammals: ear-tattoo as an alternative to toe-clipping. J Zool Lond 256: 159-163.

Mazzoglio PJ, Blengio L, Bertolino S (2007) Individual recognition in Callosciurus finlaysonii (Horsfield, 1824) (Rodentia, Sciuridae) introduced into Italy. Mammalia 71: 122-125.

Mitchell-Jones AJ, Amori G, Bogdanowicz W. Kryštufek B, Reijnders PJH, Spitzenberger F, Stubbe M, Thissen JBM, Vohralik V, Zima J (1999) The Atlas of European Mammals. Academic Press, London, UK.

Mohr E (1965) Altweltliche Stachelschweine. Westarp Wissenschaften, A. Ziemsen Verlag, Wittenburg Lutherstadt, Germany.

Molony SE, Dowding CV, Baker PJ, Cuthill IC, Harris S (2006) The effects of translocation and temporary captivity on wildlife rehabilitation success: an experimental study using European hedgehogs (Erinaceus europaeus). Biol Cons 130: 530-537.

Mori E, Giovani A (2012) Local extinction of Bombina pachypus Bonaparte, 1838 in three stations: a 17 years survey in pSCI "Poggi di Prata" (Southern Tuscany, Italy). Herp Notes 5: 407-410.

Mori E, Menchetti M, Ferretti F (2014) Seasonal and environmental influences on the calling behaviour of Eurasian Scops Owls. Bird Study 61: 277-281.

Mori E, Maggini I, Menchetti M (2014) When quills kill. The defence strategy of the crested porcupine Hystrix cristata L., 1758. Mammalia 78: 229-234.

Morris PA (1988) A study of home range and movements of hedgehogs (Erinaceus europaeus). J Zool Lond 214: 433-449.

Morris PA (2006) The new hedgehog book. British Natural History Series, Whitter Books, Yatesbury, UK.

Parkes J (1975) Some aspects of the biology of the hedgehog (Erinaceus europaeus L.) in the Manawatu, New Zealand. New Zeal J Zool 2: 463-472.

Petit S, Waudby HP, Walker AT, Zanker R, Rau G (2012) A non-mutilating method for marking small wild mammals and reptiles. Austr J Zool 60: 64-71.

Pigozzi G (1988) Quill-marking, a method to identify crested porcupines individually. Acta Theriol 33: 138-142.

Pucek Z (1981) Keys to vertebrates of Poland mammals. PWN Polish Scientific Publisher, Warszawa, Poland.

Rautio A, Valtonen A, Kunnasranta M (2013) The effects of sex and season on home range in European hedgehogs at the northern edge of the species range. Ann Zool Fennici 50: 107-123.

Rautio A, Valtonen A, Auttila M, Kunnasranta M (2014) Nesting patterns of European hedgehogs (Erinaceus europaeus) under northern conditions. Acta Theriol 59: 173-181.

Reeve N (1994) Hedgehogs. Academic Press Editions, London, UK.

Riber AB (2006) Habitat use and behaviour of European hedgehogs Erinaceus europaeus in a Danish rural area. Acta Theriol 51: 363-371.

Rodriguez Recio M, Mathieu R, Latham MC, Latham ADM, Seddon PJ (2013) Quantifying fine-scale resource selection by introduced European hedgehogs (Erinaceus europaeus) in ecologically sensitive areas. Biol Inv 15: 1807-1818. 
Sayigh LS, Tyack PL, Wells RS, Solow AR, Scott MD, Irvine AB (1998) Individual recognition in wild bottlenose dolphins: a field test using playback experiments. Anim Behav 57: 41-50.

Shanahan DF, Mathieu R, Seddon PJ (2007) Fine-scale movement of the European hedgehog: an application of spool-and-thread tracking. N Zeal J Ecol 31: 160-168.

Silvy NJ, Lopez RR, Peterson MJ (2005) Wildlife marking techniques. In: Techniques for wildlife investigations and management. Bethesda, The Wildlife Society: 339-363.

Vincent JFV, Owers P (1986) Mechanical design of hedgehog spines and porcupine quills. J Zool Lond 210: 55 75.

Young RP, Davison J, Trewby ID, Wilson GJ, Delahay RJ, Doncaster CP (2006) Abundance of hedgehogs (Erinaceus europaeus) in relation to the density and distribution of badgers (Meles meles). J Zool Lond 269: 349-35.

\section{Tables}

Table 1. Summary of captured individuals, site of capture, sex, age and biometrical measurements. Number of recaptures was also reported, as well as recapture occurrence after hibernation (November-March) and maximum distances at which each marked hedgehog was observed from the capture site. 


\begin{tabular}{lllllllll}
\hline Individual & Site & Sex & Age & $\begin{array}{l}\text { Hind foot } \\
\text { (cm) }\end{array}$ & Weight (g) & N. recaptures & $\begin{array}{l}\text { Recapture } \\
\text { after } \\
\text { hibernation }\end{array}$ & $\begin{array}{l}\text { Maximum } \\
\text { distance (m) }\end{array}$ \\
\hline 1 & & & & & & & Yes & 543 \\
2 & DW & M & Adult & 4.8 & 960 & 3 & No & 612 \\
3 & DW & F & Adult & 4.6 & 870 & 5 & No & 500 \\
4 & DW & M & Adult & 4.6 & 990 & 7 & Yes & 128 \\
5 & DW & M & Adult & 4.7 & 955 & 5 & No & 3766 \\
6 & DW & F & Juvenile & 3.9 & 370 & 2 & -- & -- \\
7 & DW & M & Juvenile & 4.1 & 420 & 0 & No & 907 \\
8 & DW & F & Juvenile & 4.0 & 385 & 4 & No & 860 \\
9 & DW & M & Juvenile & 3.7 & 410 & 6 & Yes & 49 \\
10 & HS & M & Adult & 5.0 & 1000 & 8 & Yes & 2953 \\
11 & HS & M & Juvenile & 3.6 & 400 & 7 & No & 103 \\
12 & HS & F & Adult & 4.7 & 1100 & 3 & -- & -- \\
\hline
\end{tabular}

\section{Figures}

Figure 1. European hedgehog marked with Method 1 (A), and with Method 2 (B).
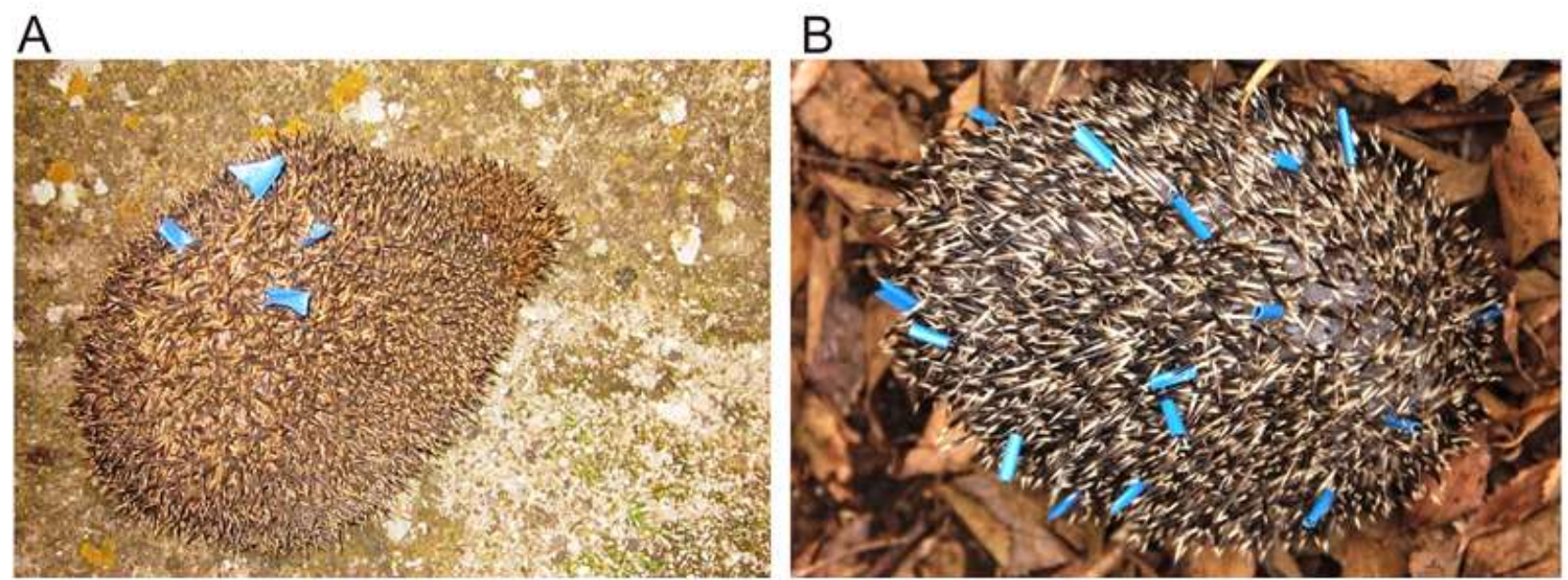

Figure 2. Median number of marked quills retained by hedgehogs at different times after marking: bars represented standard deviation, values in italics the number of hedgehogs observed at each time. 


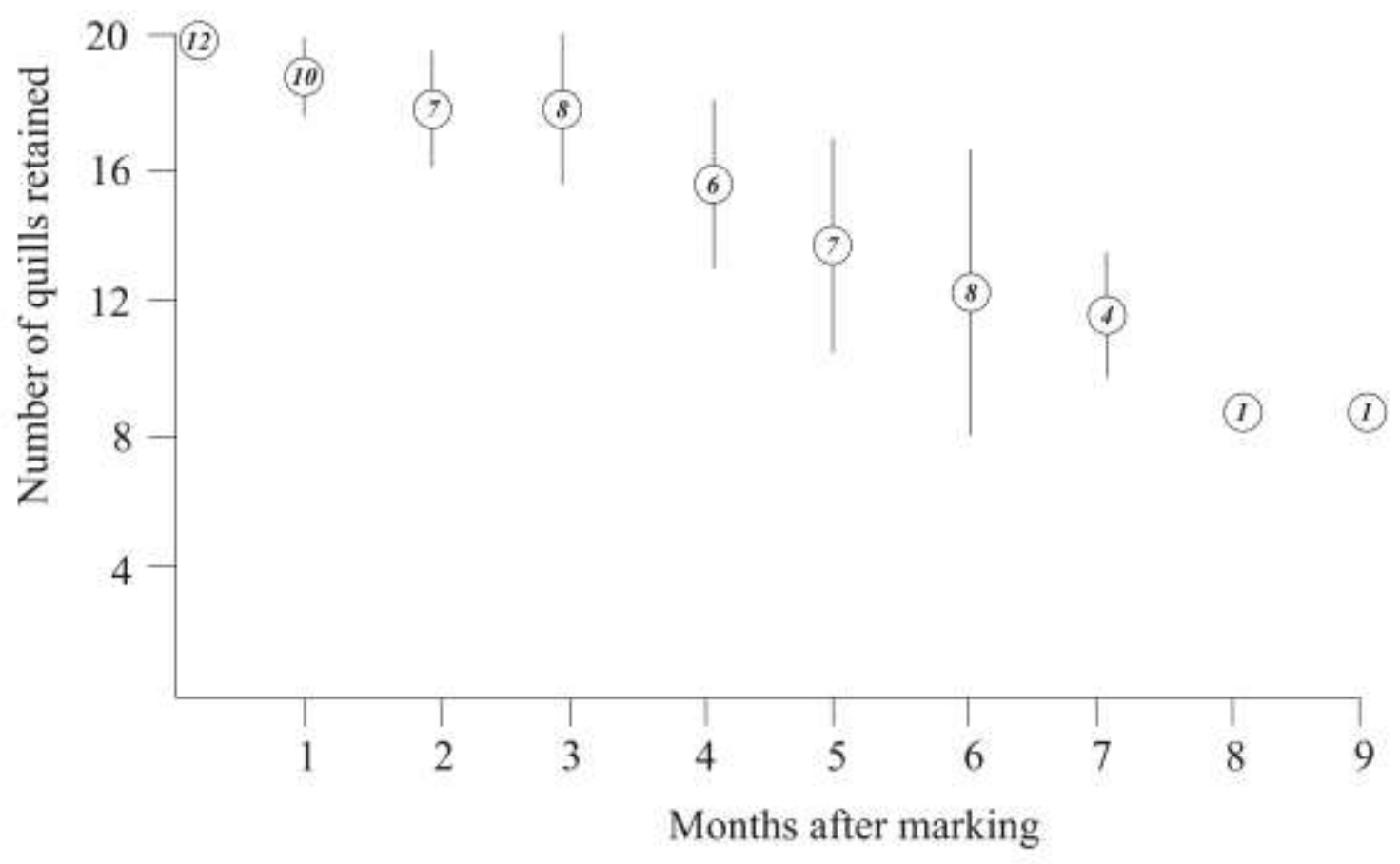

Figure 3. Body areas for marking hedgehogs.

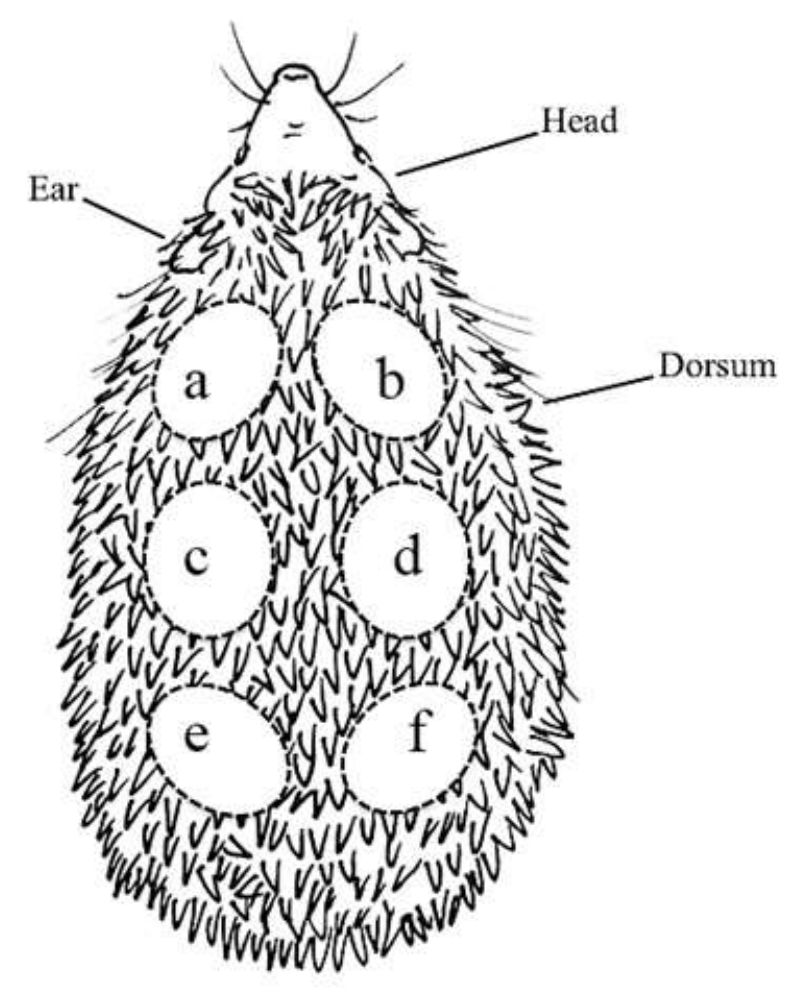

